Unnes Journal of Public Health

\title{
BUKU GIZI BRAILLE SEBAGAI MEDIA PENDIDIKAN UNTUK MENINGKATKAN PENGETAHUAN ANAK TUNANETRA
}

\section{Resa Wahyuni ${ }^{\bowtie}$, Galuh Nita Prameswari}

Jurusan Ilmu Kesehatan Masyarakat, Fakultas Ilmu Keolahragaan, Universitas Negeri Semarang, Indonesia

\section{Info Artikel}

Sejarah Artikel:

Diterima Agustus 2015

Disetujui Agustus 2015

Dipublikasikan Januari

2016

\section{Keywords:}

Knowledge; Blind; Book;

Braille

\begin{abstract}
Abstrak
Anak tunanetra memiliki resiko yang sama seperti anak normal untuk mengalami masalah gizi karena kurangnya pengetahuan gizi, sehingga diperlukan pendidikan gizi beserta media tepat untuk dapat meningkatkan pengetahuan gizi anak-anak tunanetra. Penelitian ini bertujuan untuk mengetahui apakah terdapat perbedaan signifikan antara pengetahuan gizi buah dan sayur sebelum diberi dan setelah diberi media buku gizi braille pada anak tunanetra di Madrasah Ibtidaiyah Luar Biasa (MILB) Budi Asih Semarang. Jenis penelitian yang digunakan adalah pra eksperimen dengan pendekatan one group pretest posttest design. Pengambilan sampel pada penelitian ini dilakukan dengan total sampling karena jumlah populasi yang terbatas, yaitu sebanyak 7 sampel. Diperoleh rata-rata skor untuk pre test sebesar 10,57, dan rata-rata skor post test sebesar 16,71 . Berdasarkan uji $t$ test berpasangan yang telah dilakukan, diperoleh nilai sig $(0,018)<0,05$ hal ini berati terdapat perbedaan yang signifikan antara skor sebelum diberi media buku gizi braille dan setelah diberi media buku gizi braille.
\end{abstract}

\section{Abstract}

Children with visual impairment have the same risk as eyesight children to have a nutrition problems because the lack of nutrition knowledge, in order to the nutrition education is required with the appropriate media to be able to improve theirs nutrition knowledge. This study aimed to know the significant different about nutrient of fruits and vegetables knowledge before and after given nutrient book in children with visual impairment at Madrasah Ibtidaiyah Luar Biasa (MILB) Budi Asih Semarang. The type of this research was pre experiment with one group pretest posttest design approach. Sampling was used total sampling because the population was limited, there were 7 samples. The mean of pre test score was 10,57 dan post score was 16,71. Based on the paired t test, the value of sig $(0,018)<0,05$ it means there were significant differences between score before given nutrient media braille book and score after given nutrient media braille book.

(C) 2016 Universitas Negeri Semarang

\footnotetext{
Alamat korespondensi:

Gedung F1 Lantai 2 FIK Unnes

Kampus Sekaran, Gunungpati, Semarang, 50229

E-mail: resa_ikm@students.unnes.ac.id
}

ISSN 2252-6528 


\section{PENDAHULUAN}

Masalah gizi terutama gizi kurang merupakan masalah yang sering terjadi pada anak sekolah dasar. Masalah gizi tersebut secara langsung maupun tidak langsung akan menurunkan kecerdasan anak, mengganggu pertumbuhan dan perkembangan serta menurunkan produktivitas. Berdasarkan data hasil Riskesdas tahun 2013, disebutkan bahwa status gizi anak usia 5-12 tahun secara nasional, prevalensi stunting pada anak umur 5-12 tahun adalah 30,7\% (diantaranya $12,3 \%$ sangat pendek dan $18,4 \%$ pendek). Secara nasional prevalensi wasting (menurut IMT/U) pada anak umur 5-12 tahun adalah $11,2 \%$ (diantaranya $4,0 \%$ sangat kurus dan $7,2 \%$ kurus). Dan masalah kegemukan pada anak umur 5-12 tahun secara nasional masih tinggi yaitu $18,8 \%$ (diantaranya $10,8 \%$ gemuk dan $8,8 \%$ obesitas).

Salah satu penyebab masalah gizi tersebut adalah kurangnya pengetahuan gizi. Sehingga pendidikan kesehatan berperan penting dalam tercapainya hakhak kesehatan bagi semua manusia. Pendidikan kesehatan adalah sejumlah pengalaman yang berpengaruh secara menguntungkan terhadap kebiasaan, sikap, dan pengetahuan yang ada hubungannya dengan kesehatan perseorangan, masyarakat dan bangsa. Pendidikan kesehatan ini untuk mempermudah diterimanya secara suka rela perilaku yang akan meningkatkan atau menelihara kesehatan (Machfoedz \& Suryani, 2009:5).

Ketunanetraan akan membawa akibat timbulnya beberapa keterbatasan bagi penyandangnya, salah satunya adalah keterbatasan memperoleh informasi. Keterbatasan dalam hal indera penglihatan menghalangi mereka untuk memperoleh pengetahuan dari media visual. Padahal, anak-anak tuna netra tersebut memiliki resiko yang sama seperti anak awas (mereka yang dapat melihat dengan normal) untuk mengalami masalah gizi karena kurangnya pengetahuan gizi. Sehingga perlu adanya media-media pendidikan gizi yang sesuai dengan karakteristik anak tunanetra. Seperti pada penelitian Ellyza (2013) yang memberikan pendidikan gizi pada anak tunanetra dengan menggunakan booklet Braille dengan meteri pedoman umum gizi seimbang. Sehingga pengetahuan gizi anak tunanetra dapat meningkat.

Menurut Mubarak (2007:30) faktorfaktor yang mempengaruhi tingkat pengetahuan seseoang antara lain pendidikan, pekerjaan, umur, minat, pengalaman, kebudayaan lingkungan sekitar, informasi, motivasi, serta fasilitas belajar dan sumber materi. Pengetahuan gizi sangat penting dimiliki oleh setiap orang. Kurangnya pengetahuan gizi atau kemampuan untuk menerapkan informasi tersebut dalam kehidupan sehari-hari merupakan faktor penting dalam masalah gizi. Pada Penelitian Hermina (2009), menunjukkan adanya hubungan antara pengetahuan dengan kebiasaan sarapan. Hal ini menunjukkan bahwa pengetahuan berperan penting dalam perilaku keseharian, seperti sarapan pagi.

Pendidikan kesehatan adalah proses perubahan perilaku dinamis, dimana perubahan tersebut bukan sekedar proses transfer materi/ teori dari seseorang ke orang lain dan bukan pula seperangkat prosedur, akan tetapi perubahan tersebut terjadi adanya kesadaran dari dalam diri individu, kelompok, atau masyarakat sendiri (Mubarak, 2007:8). Berdasarkan penelitian Damayanthi (2013) pendidikan 
gizi informal melalui penyuluhan pada penjaja makanan sudah efektif dalam meningkatkan pengetahuan, sikap, dan praktek penjual makanan tentang gizi dan keamanan pangan.

Metode pendidikan kesehatan dibagi menjadi tiga yaitu metode individual, metode kelompok, dan metode massa. Agar pendidikan kesehatan dapat diterima dengan baik, maka diperlukan pula media yang tepat untuk menyampaikannya. Media pendidikan kesehatan pada hakikatnya adalah alat bantu pendidikan. Alat-alat tersebut merupakan saluran (channel) untuk menyampaikan pesan-pesan kesehatan (Notoatmodjo, 2007:130). Masing-masing alat bantu memiliki intensitas yang berbeda-beda dalam membantu persepsi seseorang. Menurut Penelitian Hidayat (2009) diketahui bahwa ada perbedaan signifikan kemampuan praktik bagi petugas daerah sebelum dan sesudah sosialisasi buku pedoman penerapan gizi seimbang. Hal ini menunjukkan bahwa media berperan dalam peningkatan pengetahuan yang pada akhirnya berdampak kepada peningkatan kemampuan seseorang. Dalam penelitian Permanasari (2013) juga menunjukkan peran media buku bergambar dalam meningkatkan pengetahuan gizi siswa PAUD. Penelitian lain yang menunjukkan pengaruh media terhadap peningkatan pengetahuan adalah penelitian Herman (1990), bahwa hasilnya adalah terjadi peningkatan pengetahuan gizi ibu-ibu setelah diberikan informasi melalui media leaflet. Berdasarkan fungsinya sebagai penyaluran pesan-pesan kesehatan, media dibagi menjadi tiga, yaitu media cetak, media elektronik, dan media papan (Notoatmodjo, 2007:130).

Sekolah berkedudukan strategis dalam upaya pendidikan kesehatan melalui promosi kesehatan, karena (1) sebagian besar anak-anak berada dengan lembaga pendidikan dalam waktu yang lama (mulai taman kanak-kanak sampai sekolah lanjutan atas); (2) di sekolah anak bisa mempelajari berbagai pengetahuan termasuk kesehatan. Kegiatan ini akan membantu meningkatkan kesehatan siswa, guru dan karyawan, orang tua serta masyarakat lingkungan sekolah (Notoatmodjo,2012:40)

Sekolah adalah perpanjangan tangan keluarga dalam meletakkan dasar perilaku kesehatan. Populasi anak sekolah di dalam suatu komunitas adalah cukup besar, antara 40-50\%. Selain itu, anak sekolah merupakan kelompok yang sangat peka untuk menerima perubahan karena mereka sedang berada pada taraf pertumbuhan dan perkembangan. Pada tahap ini, anak dalam kondisi peka terhadap stimulasi, sehingga mudah dibimbing, diarahkan, dan ditanamkan kebiasaan-kebiasaan hidup sehat (Notoatmodjo, 2005:362).

Pendidikan gizi merupakan bidang pengetahuan yang memungkinkan seseorang memilih dan mempertahankan pola makan berdasar prinsip-prinsip ilmu gizi. Pendidikan ini dilakukan melalui individu maupun kelompok, diskusi, pertemuan, buku, majalah, radio, televisi, dan berbagai cara serta media lainnya. Unttuk lingkup sekolah, maka pendidikan gizi diberikan kepada siswa untuk mengarahkan kebiasaan dan cara makan kearah yang lebih baik. Maksudnya sebagai sarana untuk mempengaruhi perilaku anak, sehingga pengetahuan gizi yang diperoleh dapat diterapkan dalam kehidupan seharihari (Santoso dan Ranti, 2013:143).

Pendidikan kesehatan membutuhkan media-media yang tepat pula sebagai penunjang keberhasilannya. Menurut Machfoedz dan Suryani (2009:137) yang 
dimaksud dengan media pendidikan kesehatan adalah alat bantu pendidikan. Disebut media pendidikan karena alat-alat tersebut merupakan saluran untuk mempermudah penerimaan pesan-pesan kesehatan tersebut bagi masyarakat.

Berdasarkan observasi pendahuluan di Madrasah Ibtidaiyah Luar Biasa (MILB) Budi Asih Semarang pada tahun ajaran 2014/2015, diketahui bahwa sebanyak 71,4 $\%$ siswa dari 7 orang siswa tunanetranya memiiki pengetahuan gizi seimbang yang masih kurang. Selain itu, di Madrasah Ibtidaiyah Luar Biasa (MILB) Budi Asih juga belum terdapat media pendidikan kesehatan, khususnya pendidikan gizi.

Mengingat hal tersebut, maka keberadaan media dalam pendidikan kesehatan mutlak diperlukan oleh para tenaga kesehatan. Media akan membantu dalam melakukan pendidikan kesehatan masyarakat, karena pesan-pesan kesehatan dapat disampaikan secara lebih jelas, sehingga sasaran (masyarakat) akan menerima pesan tersebut dengan jelas dan tepat. Disamping itu, melalui media masyarakat mampu memahami fakta kesehatan yang dianggap rumit (Suiraoka \& Supriasa, 2012:3).

Menurut penelitian para ahli indera, informasi paling banyak disalurkan ke dalam otak adalah berasal dari mata. Kurang lebih $75 \%$ sampai $87 \%$ dari pengetahuan manusia disalurkan dari mata. Sedangkan $13 \%$ sampai $25 \%$ lainnya tersalur melalui indera yang lain (Fitriani, 2011:169).

Beberapa jenis media yang lazim dipakai dalam kegiatan belajar mengajar khususnya di Indonesia antara lain adalah media grafis, media berbasis audio-visual, media proyeksi diam. Sedangkan macammacam media berdasarkan jenisnya antara lain adalah media auditif (mengandalkan kemampuan suara), media visual (mengandalkan indera penglihatan), media audio visual (terdiri dari audio visual diam, dan audio visual gerak) (Mubarak \& dkk, 2007:150). Namun bagi mereka yang memiliki keterbatasan fisik, seperti pada anak tunanetra, tidak semua media dapat diterapkan dengan baik. Karena terdapat beberapa keterbatasan dalam diri mereka untuk menagkap isi dari media tersebut.

Menurut Direktorat Pembinaan Sekolah Luar Biasa yang dimaksud dengan tunanetra adalah mereka yang memiliki hambatan penglihatan atau tidak berfungsinya penglihatan sehingga mengalami beberapa keterbatasan (Widjaya, 2012:12). Sehingga pada anak tunanetra akan kehilangan banyak sumber informasi yang ditangkap oeh indera penglihat. Untuk mengurangi kerugian akibat kehilangan fungsi penglihatan, maka pada penyandang tunanetra perlu dilatih dria-dria non visual yang masih berfungsi (Rudiyati, 2009).

Anak tunanetra belajar membaca dengan menggunakan cara yang khusus yaitu menggunakan huruf Braille. Huruf Braille digunakan sebagai pengganti huruf latin, terdiri atas titik-titik yang ditimbulkan dan dibaca dengan menggunakan jari-jari (perabaan). Rudiyati dalam penelitiannya (2006) menyebutkan bahwa guru perlu memperhatikan media komunikasi yang digunakan oleh anak-anak berkelainan, antara lain media baca tulis Braille, baca tulis huruf visual yang ukurannya diperbesar, bahasa isyarat, bahasa ujaran dan atau komunikasi total.

Media pembelajaran pada anak-anak berkebutuhan khusus memiliki kekhususan sesuai karakteristik siswanya. Misalnya saja, sumber belajar anak tunanetra yang dirancang untuk memfasilitasi kegiatan belajar bagi anak tunanetra. Ada dua 
macam sumber belajar yaitu sumber belajar by designed, dan sumber belajar yang tinggal memanfaatkan by utilization. Sumber belajar by designed adalah sumber belajar yang dirancang spesifik bagi keperluan anak tunanetra dalam belajar secara formal direncanakan. Contohnya buku teks braille, buku paket braille, buku bicara "talking books", buku teks dan buku paket dengan tulisan yang diperbesar, dll. Sedangkan sumber belajar yang tinggal memanfaatkan by utilization tidak spesifik dirancang untuk keperluan pembelajaran anak tunanetra, hanya saja dapat dimanfaatkan untuk keperluan pembelajaran. Contohnya kebun, taman, pasar, pertokoan, tokoh masyarakat, dll (Yuliawati, 2013: 171). Nurta dalam penelitiannya (2013) mengemukakan bahwa melalui modifikasi bahan ajar, seperti kartu kata, baik digunakan dalam meningkatkan kemampuan membaca pada anak low vision. Dalam penelitian Martuti (2011) menunjukkan bahwa hasil belajar dari pelaksanaan model modifikasi bahan ajar siswa tunanetra meningkatkan rasa percaya diri, terbukti dari keberanian siswa bertanya pada guru, mengemukakan pendapat di depan teman-temannya, dan bertanya pada teman yang lebih pandai.

Berdasarkan karakteristik sasaran pendidikan kesehatan yaitu anak tunanetra, maka Buku Gizi Braille dipilih sebagai media pendidikan gizi anak tunanetra. Buku gizi Braille bagi anak penyandang tuna netra ini adalah media pendidikan kesehatan yang berbentuk buku yang disusun dengan huruf-huruf Braille dengan materi yang berisi tentang gizi pada buah dan sayur. Dipilih materi tentang buah dan sayur karena buah dan sayur sendiri adalah bahan pangan yang harusnya dikonsumsi setiap harinya. Dan mengkonsumsi buah dan sayur sendiri merupakan salah satu pesan yang ada dalam materi gizi seimbang. Diharapkan nantinya media buku gizi Braille tersebut dapat meningkatkan pengetahuan anak-anak penyandang tunanetra mengenai gizi buah dan sayur.

Tujuan dari penelitian ini adalah untuk mengetahui bagaimanakan gambaran skor pengetahuan gizi buah dan sayur pada anak tunanetra di Madrasah Ibtidaiyah Luar Biasa (MILB) Budi Asih Semarang sebelum dan juga setelah diberi media buku gizi braille. Kemudian dapat diketahui apakah terdapat perbedaan yang signifikan pengetahuan gizi sebelum dan sesudah diberi media buku gizi Braille tentang buah dan sayur bagi anak tunanetra di Madrasah Ibtidaiyah Luar Biasa (MILB) Budi Asih Semarang.

\section{METODE}

Jenis penelitian yang digunakan adalah pra eksperimen dengan pendekatan one group pretest posttest design. Penelitian ini dilakukan di MILB Budi Asih Semarang. Pengambilan sampel pada penelitian ini dilakukan dengan total sampling karena jumlah populasi yang terbatas, yaitu sebanyak 7 sampel. Sumber data pada penelitian ini berupa data primer dan data sekunder. Instrumen yang digunakan adalah kuesioner, dengan sebelumnya melalui uji validitas reabilitas. Untuk teknik pengambilan data pada penelitian ini adalah dengan metode pengamatan, metode wawancara, serta metode dokumentasi. Pada tahap pra penelitian dilakukan koordinasi mengenai segala sesuatu yang berhubungan dengan penelitian kepada kepala sekolah dan guru Madrasah Ibtidaiyah Luar Biasa (MILB) Budi Asih Semarang, kemudian dilakukan pengarahan pada kelompok eksperimen 
tentang prosedur pelaksanaan pendidikan gizi pada buah dan sayur melalui buku gizi braille. Pada tahap penelitian dilakukan pretest, setelah itu diberi intervensi, dan terakhir adalah posttest yang yang berjarak 15 hari dari pretest. Tahap intervensi berupa pendidikan gizi menggunakan buku gizi braille tentang manfaat buah dan sayur yang dilakukan sebanyak dua kali pertemuan. Siswa responden diberi baku gizi braille, kemudian diberi penjelasan sesuai materi yang ada dalam buku dan disertai pemberian contoh nyata buah dan sayur seperti yang ada di dalam materi. Analisis data dilakukan secara univariat dan bivariat, analisis bivariat dilakukan dengan uji $t$ test berpasangan karena data terdistribusi normal.

\section{HASIL DAN PEMBAHASAN}

\section{Distribusi Responden menurut Umur}

Distribusi responden berdasarkan umur dapat digambarkan pada tabel di bawah ini:

Tabel 1. Distrusi Responden Menurut Umur

\begin{tabular}{llll}
\hline No & $\begin{array}{l}\text { Umur } \\
\text { (Tahun) }\end{array}$ & Jumlah & Persentase \\
\hline 1. & 7 & 1 & $14,3 \%$ \\
2. & 8 & 2 & $28,5 \%$ \\
3. & 10 & 1 & $14,3 \%$ \\
4. & 12 & 3 & $42,85 \%$ \\
Total & & 7 & $100 \%$ \\
\hline
\end{tabular}

Berdasarkan tabel 1 tentang distribusi responden menurut umur, diketaui bahwa kelompok eksperimen terdapat 1 responden $(14,3 \%)$ yang berusia 7 tahun, 2 responden $(28,5 \%)$ yang berusia 8 tahun, 1 responden $(14,3 \%)$ yang berusia 10 tahun, dan 3 responden $(42,85 \%)$ yang berusia 12 tahun. Secara keseluruhan, jumlah responden dalam penelitian ini adalah 7 orang responden.
Distribusi Responden menurut Jenis Kelamin Distribusi responden berdasarkan jenis kelamin, diketahui bahwa 7 responden $(100 \%)$ berjenis kelamin laki-laki, dan tidak ada yang berjenis kelamin perempuan. Hal ini berarti seluruh responden dalam penelitian ini berjenis kelamin laki-laki.

\section{Skor Pengetahuan Siswa Sebelum dan Sesudah} Pemberian Media Buku Gizi Braille

Tabel 2 Distribusi Skor Pengetahuan responden Sebelum dan Sesudah pemberian Pendidikan Gizi Menggunakan Buku Gizi Braille

\begin{tabular}{lllllll}
\hline Waktu Pengambilan Test & N & Minimum & Maximum & Mean & Median & SD \\
\hline Pre test & 7 & 6 & 15 & 10,57 & 10,00 & 3,259 \\
Post test & 7 & 11 & 19 & 16,71 & 17,00 & 2,752 \\
\hline
\end{tabular}

Hasil penelitian pada siswa tunanetra di MILB Budi Asih Semarang diperoleh bahwa seluruh responden mengalami peningkatan skor sesudah pemberian pendidikan gizi menggunakan buku gizi braille. Dapat diketahui pula bahwa skor minimum siswa tunanetra sebelum pendidikan gizi menggunakan 
buku gizi braille adalah 6 dan skor maksimum adalah 15. Sedangkan nilai mean sebesar 10,57 dengan median 10,00 dan standar deviasi sebesar 3,259.

Selain itu dapat diketahui juga bahwa skor minimum siswa tunanetra setelah pendidikan gizi menggunakan buku gizi braille adalah 11 dan yang skor maximum adalah 19. Sedangkan nilai mean sebesar 10,57 dengan median 17,00dan standar deviasi sebesar 2,752.

Dari hasil tersebut dapat diketahui bahwa nilai mean posttest $(16,71)$ lebih baik daripada nilai mean pretest $(10,57)$ artinya terjadi peningkatan pengetahuan pada siswa tunanetra di MILB Budi Asih sesudah pemberian pendidikan gizi menggunakan buku gizi braille. Nilai mean pengetahuan gizi siswa tunanetra sebelum penyuluhan lebih rendah daripada nilai mean sesudah penyuluhan menggunakan media buku gizi braille karena kurangnya informasi yang didapat mengenai gizi.

\section{Uji Normalitas Data}

Tabel 3. Hasil Uji Normalitas Data

\begin{tabular}{ll}
\hline Waktu Pengujian Tes & Shapiro Wilk (Sig) \\
\hline Pre Test & 0,876 \\
Post Test & 0,095 \\
\hline
\end{tabular}

Berdasarkan tabel 2 tentang hasil uji normalitas data, diketahui bahwa nilai $\mathrm{p}$ value pada pre test yaitu 0,876 sedangkan pada post test adalah 0,095 . Karena nilai probabilitas ( $\mathrm{p}$ value) pada pre test dan post test keduanya lebih besar dari 0,05 maka dapat disimpulkan bahwa semua data terdistribusi normal dan bisa diuji hipotesisnya menggunakan uji statistik $\mathrm{t}$ test berpasangan.

\section{Perbedaan Skor Pre Test dan Post Test}

Tabel 4. Hasil Uji T Test Berpasangan

\begin{tabular}{lccc}
\hline Waktu Pengambilan Test & Mean & SD & Sig \\
\hline Pre test \& Post test & 6.143 & 1.773 & 0,018
\end{tabular}

Berdasarkan tabel 4 tentang hasil uji $\mathrm{t}$ test tersebut tersebut diketahui bahwa nilai mean dari pretest dan posttest adalah sebesar 6,143 dan nilai standar deviasi sebesar 1,773. Karena nilai sig $(0,018)<0,05$ maka dapat disimpulkan bahwa terdapat perbedaan yang signifikan antara pre test dan post test.

Menurut penelitian para ahli indera, informasi paling banyak disalurkan ke dalam otak adalah mata. Kurang lebih $75 \%$ sampai $87 \%$ dari pengetahuan manusia disalurkan dari mata. Sedangkan 13\% sampai 25\% lainnya tersalur melalui indera yang lain (Fitriani, 2011:169). Sehingga pada anak tunanetra akan kehilangan banyak sumber informasi yang ditangkap oleh indera penglihat. Untuk mengurangi kerugian akibat kehilangan fungsi penglihatan, maka pada penyandang tunanetra perlu dilatih dria-dria non visual yang masih berfungsi (Rudiyati, 2009). Media buku gizi braille ini dirasa tepat sebagai media pendidikan gizi bagi anak tunanetra karena ditulis dalam huruf braille. Selain itu, pemberian contoh nyata dari 
buah dan sayur sesuai isi materi juga membantu penerimaan informasi yang diberikan.

Karena terdapat signifikansi skor pengetahuan sebelum dan sesudah diberi media bergambar timbul, maka dapat ditarik kesimpulan bahwa buku gizi Braille dapat dipakai dengan baik sebagai media pendidikan gizi untuk meningkatkan pengetahuan gizi buah dan sayur anak tunanetra di MILB Budi Asih Semarang tahun ajaran 2014/2015. Hal ini sejalan dengan penelitian yang dilakukan Ulya (2013) tentang pendidikan gizi pada anak tunanetra di Kota Semarang dengan menggunakan booklet Braille. Dengan meningkatnya pengetahuan gizi, tentunya hal ini akan berdampak pada penerapan informasi yang telah didapat ke dalam kehidupan sehari-hari. Seperti pada penelitian Hermina (2009), menunjukkan adanya hubungan antara pengetahuan dengan kebiasaan sarapan. Hal ini menunjukkan bahwa pengetahuan berperan penting dalam perilaku keseharian, seperti sarapan pagi.

Media buku gizi Braille dapat digunakan sebagai media pendidikan gizi untuk meningkatkan pengetahuan gizi anak tunanetra karena media ini disesuaikan dengan karakteristik responden, yaitu anak tunanetra. Media memiliki peran penting dalam pendidikan gizi karena dapat membantu menyampaikan informasi agar dapat diterima dengan baik. Hal tersebut dibuktikan dengan berbagai penelitian mengenai peningkatan pengetahuan melalui media seperti dalam penelitian Permanasari (2013), menunjukkan peran media buku bergambar dalam meningkatkan pengetahuan gizi siswa PAUD. Penelitian lain yang menunjukkan pengaruh media terhadap peningkatan pengetahuan adalah penelitian Herman (1990), bahwa hasilnya adalah terjadi peningkatan pengetahuan gizi ibu-ibu setelah diberikan informasi melalui media leaflet.

Buku ini ditulis dalam huruf braille sehingga memudahkan anak-anak tunanetra yang menjadi responden dalam penelitian ini untuk membaca dan memahami isi buku tersebut. Selain itu, pemberian contoh nyata dari buah dan sayur yang ada dalam materi juga turut membantu mempermudah responden dalam menerima informasi gizi yang diberikan. Karena responden tidak hanya membaca ini materi, akan tetapi juga meraba, membau, dan merasakan contoh nyata buah dan sayur tersebut.

\section{SIMPULAN DAN SARAN}

Skor pengetahuan gizi buah dan sayur pada anak tunanetra di Madrasah Ibtidaiyah Luar Biasa (MILB) Budi Asih Semarang sebelum diberi media buku gizi braille memiliki rata-rata (mean) sebesar 10,57 sedangkan rata-rata (mean) sesudah diberi media sebesar 16,71. Karena nilai sig $(0,018)<0,05$, maka dapat disimpulkan bahwa terdapat perbedaan yang signifikan skor pre test dan post test pengetahuan gizi buah dan sayur anak tunanetra di MILB Budi Asih Semarang tahun ajaran 2014/2015.

Hasil penelitian ini dapat dijadikan pertimbangan untuk diterapkannya pendidikan gizi pada anak-anak berkebutuhan khusus, utamanya bagi anak tunantra. Sehingga terdapat perkembangan media-media pendidikan gizi bagi anak tunanetra. 


\section{UCAPAN TERIMAKASIH}

Penulis mengucapkan terimakasih kepada kepala sekolah Madrasah Ibtidaiyah Luar Biasa (MILB) Budi Asih Semarang yang telah memberikan ijin penelitian, Indra

Damayanthi, E., Khotimah, K., Mudjajanto, E.S., Dwiriani, C.M., \& Kustiyah, L. (2013). Jurnal Penelitian Gizi Makan. Pendidikan Gizi Informal Kepada Penjaja Makanan untuk Peningkatan Keamanan Pangan Jajanan Anak Sekolah Dasar, 36(1), 20-30.

Fitriani, S. (2011). Promosi Kesehatan. Yogyakarta: Graha Ilmu.

Herman, S. (1990). Jurnal Penelitian Gizi Makan. Penggunaan Leaflet dalam Pendidikan Gizi dan Pengaruhnya terhadap Tingkat Pengetahuan Ibu, 13,39-46.

Hermina., Nofitasari, A., \& Anggorodi, R. (2009). Jurnal Penelitian Gizi Makan. Faktor-faktor yang mempengaruhi Kebiasaan Makan Pagi Pada Remaja Putri di Sekolah Menengah Pertama (SMP), 32(2), 94-100.

Hidayat, TS., \& Jahari, A.B. (2009). Jurnal Penelitian Gizi Makan. Uji Coba Pedoman Aplikasi Perumusan Pesan Umum Gizi Seimbang (PUGS) Sesuai Kondisi Daerah, 32(1), 16-21.

Kementrian Kesehatan RI. (2014). Pedoman Gizi Seimbang. Jakarta: Kementrian Kesehatan RI.

Machfoedz, I., \& Suryani. E. (2009). Pendidikan Kesehatan Bagian dari Promosi Kesehatan. Yogyakarta: Fitramaya.

Martuti, R.D. (2011). Tesis. Pelaksanaan Pembelajaran Model Modifikasi Bahan Ajar Siswa Tunanetra di SMP Negeri 4 Wonogiri. Surakarta: Universitas Sebelas Maret.

Mubarak, W.I. (2007). Promosi Kesehatan Sebuah Pengantar Proses Belajar Mengajar dalam Pendidikan. Yogyakarta: Graha Ilmu.

Notoatmodjo, S. (2005). Promosi Kesehatan Teori dan Aplikasi. Jakarta: Rineka Cipta.
Ariwibowo, S.E, M.Pd, serta staf pengajar MILB Budi Asih Semarang yang telah membantu dan mendampingi pelaksanaan penelitian.

\section{DAFTAR PUSTAKA}

--osehatan Masyarakat Ilmu dan Seni. Jakarta: Rineka Cipta.

(2012). Promosi Kesehatan di Sekolah. Jakarta: Rineka Cipta.

Nurta, Y. (2013). Jurnal Ilmiah Pendidikan Khusus,. Meningkatkan Kemampuan Membaca Kalimat Sederhana Bagi Anak Low Vision Melalui Media Krtu Kata, 1(1), 33-43.

Permanasari, Y., Luciasari, E., \& Aditianti. ( 2013). Jurnal Penelitian Gizi Makan. Pengembangan Media Edukasi Melalui Buku Mewarnai untuk Peserta Pendidikan Anak Usia Dini (PAUD), 36(1), 31-43.

Rudiyati, S. (2006). Jurnal Pendidikan Khusus. Task Analysis dan Pendekatan Fungsional-Individual dalam Pembelajaran Anak Berkelainan, 2(2), 7284.

(2009). Jurnal Pendidikan Khusus .Latihan Kepekaan Dria Non-Visual bagi Anak Tunanetra Buta, 5(2), 55-67.

Santoso, S., \& Ranti, A.L. (2013). Kesehatan dan Gizi. Jakarta: Rineka Cipta.

Suiraoka, I Putu dan I Dewa Byoman Supriasa, 2012, Media Pendidikan Kesehatan, Graha Ilmu, Yogyakarta.

Ulya, E., Budiono, I, \& Mardiana. (2014). Unnes Journal of Public Health. Efektivitas Media Booklet Braille dalam Meningkatkan Pengetahuan Gizi pada Anak Tunanetra, 3(3),48-55.

Widjaya, A. (2012). Seluk Beluk Tunanetra dab Strategi Pembelajarannya. Jogjakarta: Javalitera.

Yuliawati, F. (2013). Jurnal Pendidikan IPA Indonesia. Pengembangan Modul Pembelajaran Sains Berbasis Integrasi ISLAM-SAINS untuk Peserta Didik Difabel Netra MI/SD Kelas 5 
Resa Wahyuni dan Galuh Nita Prameswari / Unnes Journal of Public Health 5 (1) (2016)

2(2), 169-177 